\title{
A violência no teatro contemporâneo Efeitos retóricos e éticos
}

\author{
Aglika Stefanova
}

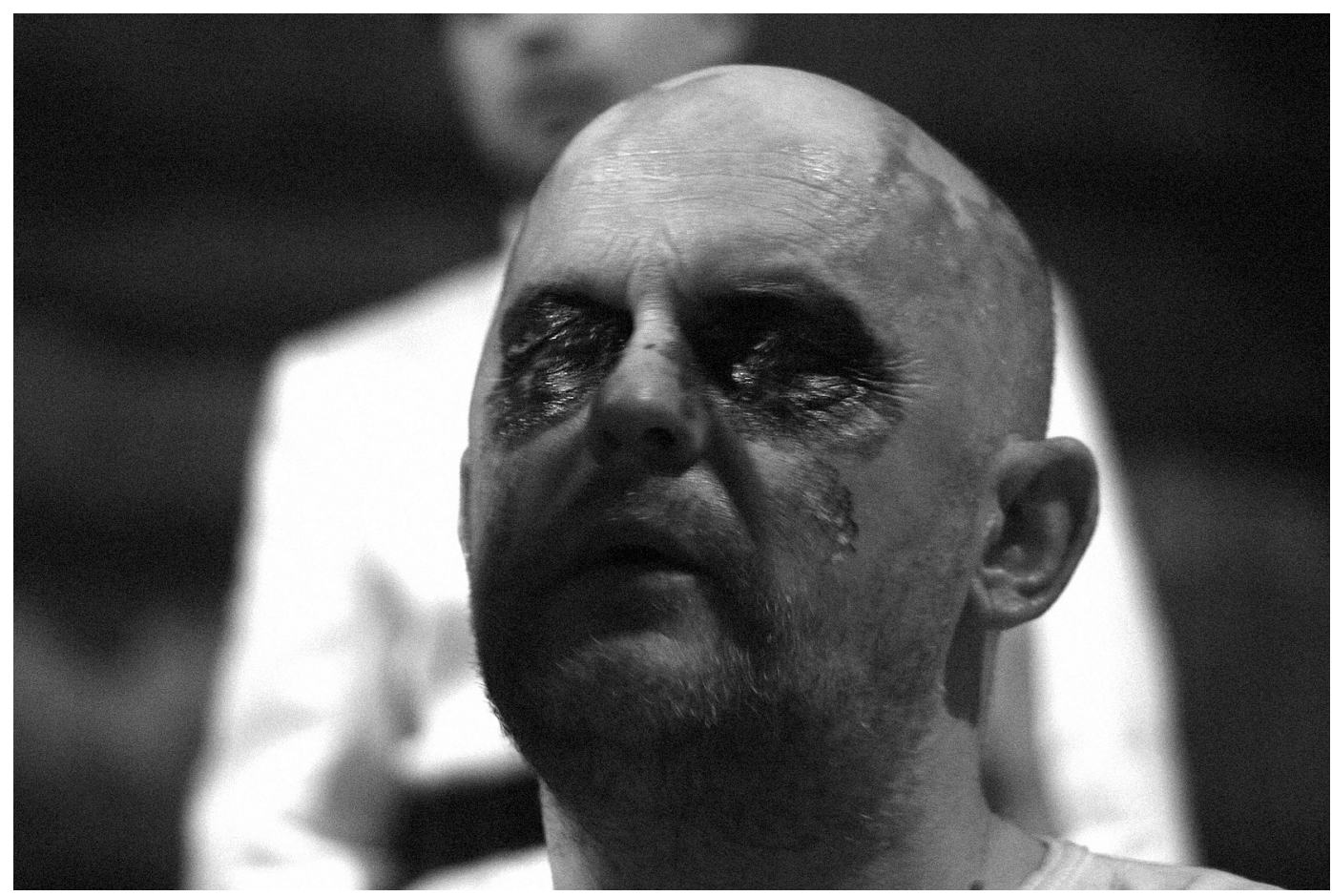

0 que é o teatro sem violência? A violência é a razão de ser do teatro: é o seu elemento temático principal, a sua verdadeira essência. 0 teatro é um laboratório cujo objecto de estudo é a violência: é nas suas tábuas que se analisam e se tratam as epidemias de violência que afectam o real e o imaginário.

Apesar dos apelos constantes para a abolição da pena de morte no mundo inteiro, as personagens de teatro continuam a morrer e a ser mortas pelos seus adversários, pelos seus autores e pelo seu destino pessoal... No teatro, a morte não pode ser abolida, nem a violência pode ser evitada. Os heróis de teatro morrem em nome do humanismo e está fora de questão que deixem de o fazer. Porque o teatro é um espaço reservado ao desassossego, à insegurança e à dúvida. Porque é ai que se escreve e comenta a história dos erros da humanidade. É o lugar onde nós comunicamos com os espectros do passado, com o nosso "Eu" arcaico.

0 teatro ajuda-nos a reencontrar a nossa posição pessoal perante a violência, a intolerância, a injustiça: é o seu papel humanista. Todas as noites a cena teatral sacrifica os seus heróis para nos ajudar a resolver os nossos problemas de hoje. Mantendo a sua forma arcaica, sem que as tecnologias modernas tenham alterado sensivelmente o seu corpo, o teatro revela-se necessário e indispensável. É arcaico devido às suas capacidades retóricas: nele os heróis são sempre mortais e sofredores. No palco confrontam-se os valores tradicionais e as novas práticas, que se impõem na vida social e na vida privada. Por isso o teatro é um espaço para a actualização ao pôr constantemente em dia as nossas perspectivas acerca da vida e ao dar-nos orientação para a pensarmos e praticarmos.

Hoje, no teatro, o homem fica entregue a estes fantasmas, visões, exigências e ambições. 0 tema principal do teatro tornou-se a tensão entre o privado e o social, entre a ambição e a capacidade de acção, entre o corpo real e as imagens idealizadas, divulgadas pelos meios de comunicação.

0 teatro descreve-nos em pormenor a maneira como os heróis escolhem o seu destino. É um instrumento de humanização porque procura a verdade e sugere valores sem os impor de forma autoritária. Com a ajuda de simples estruturas de signos, com alegorias ou metáforas delicadas, mostra-nos o sofrimento, as neuroses, os medos e a instabilidade do homem contemporâneo que, muito frequentemente, se precipita para a morte como uma opção consciente.
Aglika Stefanova é investigadora doutorada pelo Instituto de Artes Teatrais da Academia das Ciências da Bulgária, é autora de um livro sobre o melodrama do ponto de vista da teoria (2000) e de um outro sobre a dramaturgia búlgara dos anos 90 (2004). 
É isto que faz a diferença entre os heróis do teatro e os semi-deuses dos filmes hollywoodescos que morrem de maneira provisória para ressuscitarem logo a seguir. É também por isto que diferem das personagens da publicidade, que são imortais e felizes como os antigos deuses, e que irão continuar a alimentar-se eternamente com cornetos e chocolate, enquanto a heroína de Sarah Kane da peça 4:48 Psicose irá ficar morta para sempre depois das 4 horas e 48 minutos, a hora do maior número de suicídios. Evitar o tema do sofrimento e da morte é o objectivo fundamental da retórica da cultura de massas. Mas se os heróis do teatro têm sido sempre mortais e sofredores, eles são hoje em dia ainda mais mortais e sofredores.

Porque seguir as regras morais deste mundo, que é o nosso, torna-se uma tarefa cada vez mais esgotante. Todos os dias há cada vez mais provocações para com o nosso sentimento de justiça e para com a nossa natureza humana. Nós estamos demasiado bem informados acerca da sincronização da injustiça e da violência em todo o lado, no mundo inteiro. Como reagir, como hierarquizar os dados e, o que é mais importante, o que pensar acerca do homem depois de termos ao nosso dispor toda esta informação? A tragédia antiga interpretava toda a espécie de manifestação de vingança, de ódio ou de crueldade extrema como hybris, como um comportamento desumano. Contudo a tragédia antiga era compassiva: a compreensão antiga da medida e da beleza expulsava da cena a demonstração da violência e da morte. Competia aos mensageiros a função de relatar estes acontecimentos. No teatro contemporâneo a violência é o centro e o vértice do trabalho cénico, o que muitas vezes fica sem comentário. A violência ostenta-se duma maneira narcísica e teatralizada, é por demais espectacularizada.

Por outro lado, é preciso verificar que a violência no teatro é tanto física como verbal, isto é, ideológica. Lembremo-nos da célebre cena entre Lady Anne e Ricardo no Ricardo III de Shakespeare: no início ela reivindica que a maldição divina caia sobre o assassino do seu marido, e no fim aceita um anel de noivado. São os efeitos da retórica e da violência. A violência das palavras e a violência física sobrepõem-se e testemunham de modo tautológico a crise do humano. Também as peças de Tchekov estão cheias de violência: trata-se da violência exercida por certos modelos (reais) de vida sobre outros (imaginários). Mesmo na peça Arte (Art) de Yasmina Reza o facto de se gostar ou não de um quadro provoca uma violência concreta verbal e física. Tanto os gostos, como a política ou os negócios são um campo de batalha e de dominação.

Segundo a observação pertinente de Albert Camus
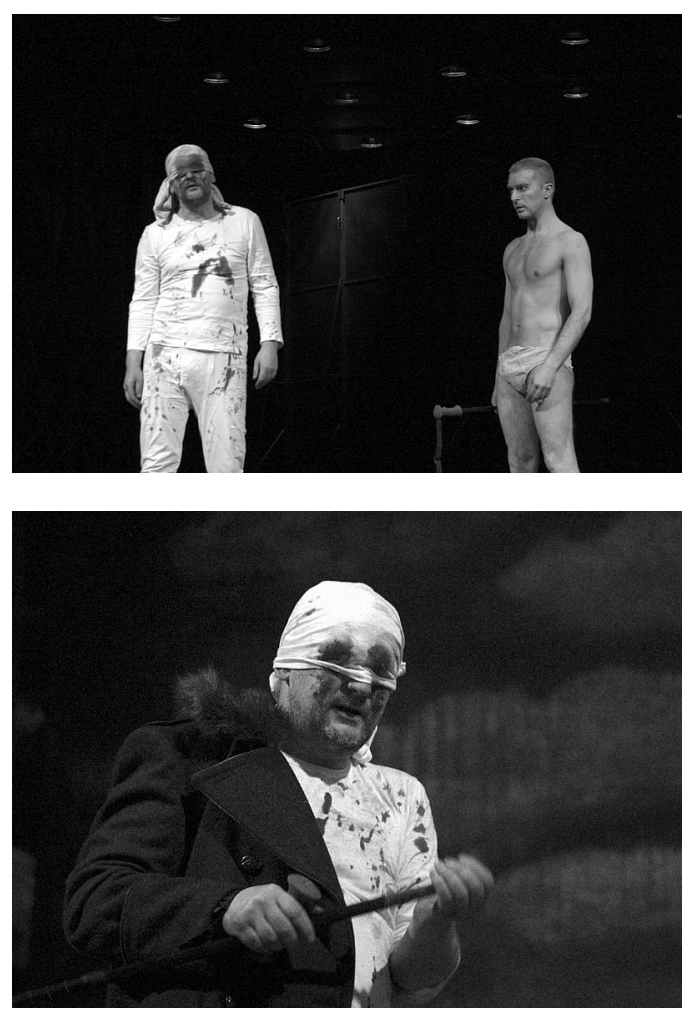

"hoje um homem ou uma força histórica são avaliados segundo o seu êxito e não segundo a norma da dignidade humana". 0 teatro é sem dúvida um lugar reservado para o humanismo porque aqui a dignidade humana é uma qualidade constante e o seu valor está determinado. Os valores que o teatro divulga, com uma teimosia secular, são intransitivos e estáveis, independentes das modas (que passam) ou das tabelas de classificação (igualmente temporárias). No teatro a regra segundo a qual "quem tem êxito é quem tem razão" ainda não conseguiu imporse. A retórica do teatro defende sempre os valores antigos e Cláudio continua a ser um assassino engenhoso, mas é, apesar disso, condenado. 0 teatro é a consciência culpada da sociedade contemporânea.

0 drama contemporâneo é muitas vezes caracterizado por uma linguagem violenta e agressiva. Contudo, pergunto-me se esta linguagem traz em si uma ameaça real ou se é antes uma forma puramente retórica que ajuda a personagem a legalizar-se na qualidade de interlocutor "perigoso" e importante. Na peça de Xavier Durringer 0 desejo de matar na ponta da língua (L'envie de tuer sur le bout de la langue) a violência das palavras parece não ter objectivo, visa só preencher o vazio no diálogo quotidiano. De facto, a linguagem agressiva não revela se é apenas uma forma retórica, um código comunicativo para os jovens, ou antes, se expressa uma ameaça verdadeira e concreta. Não será que a linguagem grosseira é utilizada por personagens demasiado sensiveis para se disfarçarem e poderem assim sobreviver no "mundo contemporâneo da violência"? 0 teatro contemporâneo tenta manter o silêncio sobre esta questão e é nesta dupla posição, pouco clara, que reside a sua força. 0 teatro não responde directamente à questão sobre quem é e como é o homem contemporâneo, mas fala daquilo que é eticamente inaceitável, fala dos perigos para a situação humana e para o humanismo. 


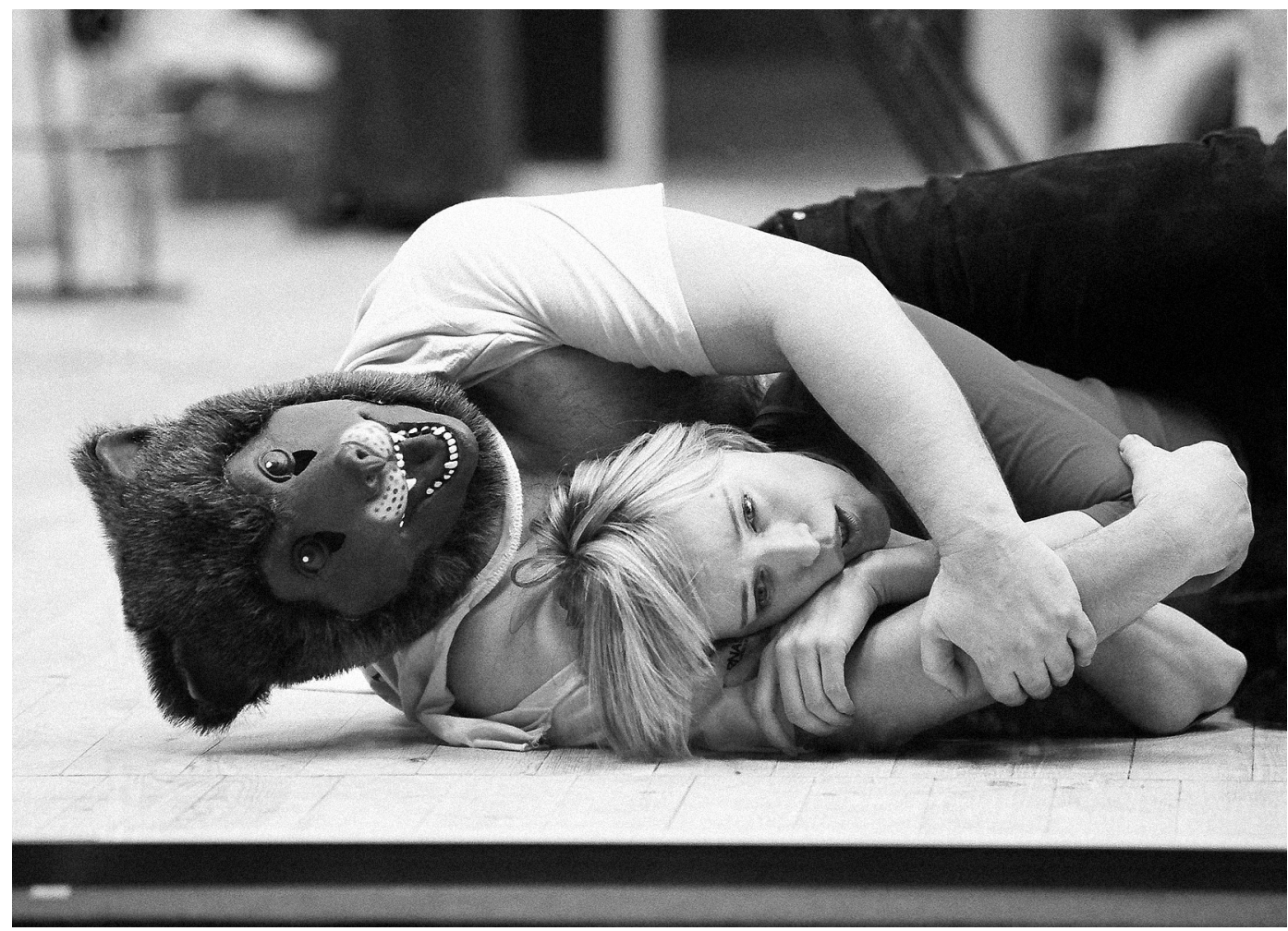

Porém aqui surge outro problema: não é possivel que, acostumado à linguagem grosseira e rude, o público acabe incapaz de discernir a retórica e a mensagem humanista dos autores clássicos? Depois da projecção do filme 0 mercador de Veneza, com Al Pacino, lembro-me que um jovem espectador exclamou: "Olha, não sabia que Shakespeare era anti-semita!" Será que os espectadores contemporâneos são capazes de distinguir a mensagem ética do "velho" teatro? Ou a sua retórica já se tornou hoje demasiado elevada e incompreensivel? É certo que o teatro é um espaço para comunicar (com o outro e consigo mesmos), mas qual é a sua eficácia hoje? Não se transformou já numa arte para minorias, uma arte que ocupa um espaço cada vez mais reduzido, e com um número de espectadores cada vez mais exíguo?

Influenciado pelas imagens naturalistas divulgadas pelos meios de comunicação, o teatro tenta talvez tornarse mais atractivo e tem muitas vezes a tentação de representar a violência através de jogos de prestidigitação e diferentes formas de ilusionismo e de truques. Isto, todavia, é contrário à retórica específica do teatro, baseada em imagens e gestos metafóricos, em quadros bastante sugestivos e muito pouco imitativos.

Encontram-se com cada vez maior frequência encenadores e actores que se transformam em ilusionistas e que, por meio da magia, tentam tornar real o falso sangue teatral. Não será que esperam uma reacção inconsciente por parte do público? Um qualquer reflexo condicionado de humanidade? Será que o sangue teatral é um sinal da "serosidade" do problema ou da mensagem, que veicula, ou antes a cor vermelha é em princípio um sinal convencional do compromisso do encenador com o humano?

Com um uso exagerado do sangue em cena o teatro visa, efectivamente, uma imitação, quase no sentido da mimese aristotélica, mas não uma imitação da natureza; ele, de facto, quer imitar é o cinema e a sua retórica específica. No entanto, a cor vermelha não é suficiente para que o público se empenhe ética, intelectual ou emocionalmente. Ao imitar o cinema, o teatro emite sinais pouco claros, errados, e confunde o seu próprio ADN, entrando em competição com David Copperfield e George Lucas. 0 sangue falso corrompe a retórica antiga e solene do teatro. É o momento de lembrar uma frase célebre de Albert Camus: "A sensibilidade do mundo deve ser poupada".

E finalmente queria partilhar convosco duas imagens de violência que me impressionaram no ano passado, na $52^{a}$ edição do festival Sterijino Pozorije, de Novi Sad. 0 maior número de prémios para todas as categorias foi alcançado pelo grande espectáculo musical Simão, o menino exposto (Siméon, l'enfant trouvé), uma peça de Milena Marcovic. Ela utilizou como base o tema de uma peça já esquecida do século XIX, de Jovan Sterija, pai do drama sérvio, e o tema é o mito de Édipo no contexto sérvio. Por outro lado o papel de Édipo foi interpretado brilhantemente pelo actor búlgaro Stefan Chterev, e o espectáculo tinha uma música de Boris Kovac que nos lembrava a musicalidade e o dramatismo dos melodramas clássicos. 0 encenador esloveno Tomi Janezic fazia evoluir na cena um quadro panorâmico da sociedade contemporânea puxando para a super produção: os bastidores desapareciam e na cena nua o público podia reparar em dois pequenos lagos e num rio onde corria água. Durante todo o espectáculo desfilavam diferentes espécies de animais rurais (em carne e osso), havia também uma criança pequena; um carro verdadeiro parava numa verdadeira estação de gasolina, uma mota passava a toda velocidade. Depois do suicídio do Édipo sérvio, o rio muda de cor e corre com uma água vermelha... A água converteuse em sangue. Esta ribeira é, sem dúvida, uma metáfora poética e teatral da violência das leis humanas e do trágico. Mas, será que esta ribeira vem directamente do tema da 
The Dismissal of the Greek Envoys, de Jan Kochanowski, enc. Michel Zadara, National Old Theatre Cracóvia, Polónia [cortesia da autora].

peça de Jovan Sterijia do século XIX ou não será antes uma ribeira relativamente contemporânea, dos anos 90 , que corre nos territórios da ex-Jugoslávia? Sem querer sair do seu tema, o espectáculo permitiu-nos estabelecer analogias contemporâneas devido à mistura da retórica do melodrama com a do naturalismo. Isto faz-me lembrar a análise de Julia Przybos, que, no seu livro L'entreprise mélodramatique, reconhece que o final do melodrama realiza uma purificação social e explica assim o grande êxito dos melodramas depois da revolução francesa de 1789: as peças "imitam raptos, roubos, assassínios, tempestades, erupções vulcânicas e inundações. Evitando cuidadosamente falar abertamente do passado traumático e sem nunca mencionar a violência revolucionária, os melodramas recriavam nos palcos - sob uma forma altamente codificada e simbólica - a história tumultuosa dos anos revolucionários e pós-revolucionários. Com a ajuda destes efeitos fortes e espectaculares, as peças apresentavam os meios que permitiam à comunidade canalizar ou anular a hostilidade."

Mais inquietante para mim foi o espectáculo Eu, ou um outro qualquer (Me, or Somebody Else), baseado na peça da jovem autora Maja Pelevic, encenada por Kokan Mladenovic. 0 enredo inspira-se directamente na história de uma menina raptada na Áustria, que viveu nove anos reclusa. Neste espectáculo o maníaco-raptor está descrito como um homem que possui uma alma extraordinária e não como um doente mental. Ele olha para as estrelas e opõe-se à sociedade de consumo, enquanto os pais da rapariga são representados por bonecos mecânicos, robôs que não sabem fazer mais nada a não ser ir e voltar do trabalho (no caso do pai) e maquilhar-se (no caso da mãe). A violência desliza furtivamente no seu mundo como um espirito antigo, para se opor à euforia da sociedade de consumo. Anos mais tarde, quando a rapariga consegue fugir da sua prisão, ela descobre a falsidade do mundo contemporâneo e sente uma imensa nostalgia pelo tempo que viveu em cativeiro.

Penso que a simples possibilidade de um tema como este e da alteração tão radical da perspectiva moral, que distingue o bem do mal, dão conta de uma crise e confusão dos valores éticos, ao mesmo tempo que procuram desculpar, justificar, e promover mesmo a violência.

A jovem autora, nascida em 1981, descreve a violência e a vida reclusa como uma variante para conservar e salvar o humano. Todos os que estão fora da casa-prisão são personagens farsescas, palhaços ou imbecis. 0 seu mundo é insuportável. Mas será que é possivel que o ser humano seja salvo do mundo à força e seja libertado à força de todos os riscos e de todos os efeitos da vida contemporânea? Não será a vida em isolamento uma questão de escolha livre e privada? Lembro-me aqui duma personagem do Calígula de Albert Camus que afirmava: "E no entanto, é preciso defender este mundo, se nele quisermos viver"

0 teatro confirma a comunicação e não o isolamento; o conflito e a forma dialógica (com o outro e consigo
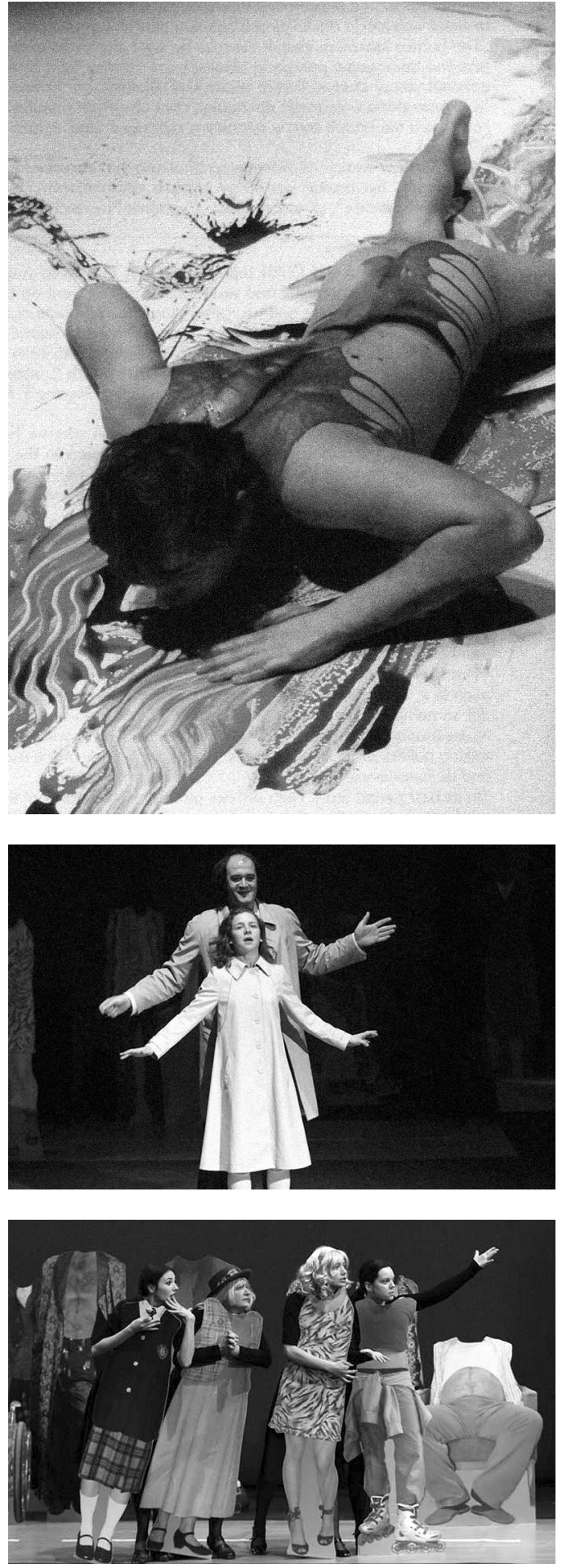

mesmo) enquanto instrumentos para atingir uma verdade maior acerca do mundo e da natureza humana.

0 teatro descreve o homem enquanto individuo activo, que sabe guiar o seu destino, e que decide sobre a sua vida e a sua morte. 0 teatro coloca-nos a todos perante uma escolha autêntica, provoca em nós a necessidade de termos uma posição e uma opinião. Eis a liberdade que nos propõe numa época em que o humano só a custo consegue anunciarse e definir-se. É esse o humanismo específico do teatro.

Tradução de Sebastiana Fadda 